\title{
Ectopic Pregnancy in a Referral Hospital in the Volta Region of Ghana West Africa
}

\section{Augustine A. Oppong1, Hope Y. Agbemenyah², Innocent Afeke3, Ibrahim Jamfaru4, Irene Attachie5, Verner N. Orish ${ }^{4}$}

${ }^{1}$ Departement of Physician Assistant, School of Medicine, University of Health and Allied Sciences, Ho, Ghana

${ }^{2}$ Department of Anatomy and Physiology, School of Medicine, University of Health and Allied Sciences, Ho, Ghana

${ }^{3}$ Department of Medical Laboratory Sciences, School of Allied Sciences, University of Health and Allied Sciences, Ho, Ghana

${ }^{4}$ Department of Microbiology and Immunology, School of Medicine, University of Health and Allied Sciences, Ho, Ghana

${ }^{5}$ Department of Midwifery School, of Nursing and Midwifery, University of Health and Allied Sciences, Ho, Ghana

Email: orishv@yahoo.com

How to cite this paper: Oppong, A.A., Agbemenyah, H.Y., Afeke, I., Jamfaru, I., Attachie, I. and Orish, V.N. (2016) Ectopic Pregnancy in a Referral Hospital in the Volta Region of Ghana West Africa. Open Access Library Journal, 3: e2983. http://dx.doi.org/10.4236/oalib.1102983

Received: August 16, 2016

Accepted: September 2, 2016

Published: September 6, 2016

Copyright $\odot 2016$ by authors and Open Access Library Inc.

This work is licensed under the Creative Commons Attribution International License (CC BY 4.0).

http://creativecommons.org/licenses/by/4.0/

cc) (i) Open Access

\begin{abstract}
Background: Ectopic pregnancy is still a global problem for women of reproductive age with increasing burden of the disease and increasing mortality especially for women living developing world like Africa. In Ghana studies evaluating the burden of ectopic pregnancy have been conducted in major centres like Korle-Bu and KATH but few in other centres. This study tends to evaluate the prevalence, clinical presentation and finding of ectopic pregnancy in a referral hospital in the Volta region of Ghana. Methodology: This was a 3 years (2013-2016) retrospective review of all gynaecological admission in the Volta regional hospital. All ectopic pregnancy cases/ record were identified, retrieved and information on the socio-demographics, clinical presentations, intraoperative findings and outcome of surgery were all extracted for analysis. Result: A prevalence of $2.05 \%$ (53/2582) was recorded over the study period. 58.5\% (31/53) of the women were married and between the age group of 21 30. $47.2 \%(25 / 53)$ had primary school education. Lower abdominal pain was common in $98.1 \%$ (52//53), 69.2\% (37/53) had vaginal bleeding while $96.4 \%(51 / 53)$. Fallopian tube pregnancy was seen in $96.2 \%(51 / 53)$ while $3.8 \%(2 / 53)$ were abdominal pregnancy. Tubal rupture and heamoperitoneum were seen in $73.6 \%(39 / 53)$ of the women. $78.4 \%$ (40/51) of the fallopian tube pregnancy occurred at the ampulla. All the women in this study were successfully managed with radical surgery. Conclusion: There is still the need to evaluate the prevalence of ectopic pregnancy in the region. Proper education of women of reproductive age and provision of equipment and skills to enable early diagnosis of ectopic pregnancy is very necessary in ensuring less radical and traumatic management with less implication on fertility of women post-surgery.
\end{abstract}




\section{Subject Areas}

\section{Gynecology \& Obstetrics, Women's Health}

\section{Keywords}

\section{Ectopic Pregnancy, Lower Abdominal Pain, Vaginal Bleeding, Transnvaginal Ultrasound, Tubal Rupture}

\section{Introduction}

Ectopic pregnancy is serious life threatening gynaecological emergency. It can be defined as the abnormal implantation of fertilized ovum or blastocyst at sites other than the endometrial cavity of the uterus and very commonly the distal portion of the fallopian tube [1]. It has an estimated global prevalence of $1 \%-2 \%$ with the United Kingdom recording 12,000 yearly translating to about $1.1 \%$ [2]. Centre for disease control in the United States of America showed an increase incidence ectopic pregnancy from $1.9 \%$ to $2.2 \%$ of live births between 1981 to 1991 [3]. In a similar study conducted in Norway between 1976 and 1993, the incidence of ectopic pregnancy increased from $1.4 \%$ to $2.2 \%$ of live births. [4].Though ectopic pregnancy is the leading cause of pregnancy-related death in early pregnancy [5], in developed countries like USA, the UK and most countries in Europe there is a steady decline of ectopic pregnancy case fatality rates despite the documented increase in prevalence [6] [7]. Unfortunately the same cannot be said with developing countries as many hospital based studies from the region reported a 10 times higher case-fatality rate compared to develop countries [8]. One of the reasons for this worrying discrepancy between developed and developing countries is late diagnosis, as these women explore other precarious unorthodox means for treatment of their problem leading to late arrival in hospital [8]. Another reason is the lack diagnostic equipment for early diagnosis like transvaginal ultrasound and $\beta$-HCG test [5] [9].

Ectopic pregnancy can present with abdominal pain, amenorrhea or vaginal bleeding. These three symptoms occurring simultaneously in a patient is known as a clinical triad and although regarded as very specific for ectopic pregnancy [10], it is absent in close to $45 \%$ of cases [11]. Lower abdominal pain is fairly constant, present in $80 \%$ $100 \%$ of cases with varied severity [2] [12]. Amenorrhea, on the other hand, is reported by $75 \%-90 \%$ [12]. Vaginal bleeding is another common symptom but $10 \%-20 \%$ of women do not present with it [13].

In Ghana, like most African countries diagnosis, treatment and management of ectopic pregnancy is still a big issue making ectopic pregnancy a threat to the health of women of reproductive age [14]. Studies done showed $10.6 \%$ burden of ectopic pregnancy in all gynecological admission in Komfo Anokye Teaching Hospital Kumasi [15] and 32.90 per 1000 deliveries in Korle-bu Teaching Hospital in Accra [14]. There is however little or no data on the prevalence or incidence of ectopic pregnancy in other 
parts of the country especially the Volta region of Ghana. This study looked at the prevalence of ectopic pregnancy and clinical presentation and findings in the Volta Regional hospital of Ghana

\section{Methodology}

\subsection{Study Area}

The study was conducted at the Volta regional Hospital located in Ho. Ho is the regional capital of Volta region of Ghana and it has a population of approximately 177,281 representing 8.4 percent of the region's total population according to the 2010 Population and Housing Census. This makes it the most populous district in the Volta Region. The hospital is a referral center which serves people from all the districts in the region and even beyond.

\subsection{Study Design}

This was a retrospective, descriptive study of ectopic pregnancies managed in Volta regional hospital during the study period (July $1^{\text {st }}, 2013$ to March 31 ${ }^{\text {st }}, 2016$ ). The hospital has a yearly admission of almost 16,000. All gynecological admissions during the study period was reviewed, and the medical records of those diagnosed and confirmed as ectopic pregnancy was retrieved and information on the age, education, marital status, occupation, parity, clinical presentation and surgical findings were collected with the aid of data-entry forms designed for this purpose. Only patient with a confirmed diagnosis of ectopic pregnancy were included in this study.

\subsection{Data Entry, Management and Analysis}

The data collected was organized with Microsoft excel 2010 and analyzed using SPSS (Statistical Package for the Social Sciences, SPSS Inc., Chicago), version 20.0 for Windows. Data was analyzed using descriptive and multiple response statistic methods. Categorical variables were presented as tables and graphs with absolute frequencies.

\subsection{Ethical Clearance}

Ethical clearance was obtained from the Ghana health service Ethics Review Committee (ERC). GHS-ERC 57/02/16.

\section{Result}

A total of 2582 cases were admitted in the gynecology ward of the hospital during the period under study. Fifty-three (2.05\%) of these cases were diagnosed as Ectopic pregnancy.

Table 1 shows the general characteristics of the women with ectopic pregnancy. Majority of the women diagnosed with ectopic pregnancy were between the ages of $21-30$ (58.5\%), and the least diagnosed are women between the ages of $10-20(7.5 \%)$ and 41 $50(3.8 \%)$. The mean age of the women in this study was $28.8 \mathrm{yrs}$ (not shown). Married women were most diagnosed $(31,58.5 \%)$ compared with single women $(16,30.2 \%)$ and 
Table 1. Characteristics of the study participants.

\begin{tabular}{|c|c|c|}
\hline Characteristics & $\mathrm{n}(53)$ & $\%$ \\
\hline \multicolumn{3}{|l|}{ Maternal age } \\
\hline $10-20$ & 4 & 7.5 \\
\hline $21-30$ & 31 & 58.5 \\
\hline $31-40$ & 16 & 30.2 \\
\hline $41-50$ & 2 & 3.8 \\
\hline \multicolumn{3}{|l|}{ Marital status } \\
\hline Single & 16 & 30.2 \\
\hline Married & 31 & 58.5 \\
\hline Co-habiting & 6 & 11.3 \\
\hline \multicolumn{3}{|l|}{ Education } \\
\hline None & 16 & 30.2 \\
\hline Primary & 25 & 47.2 \\
\hline Secondary and higher & 12 & 22.6 \\
\hline \multicolumn{3}{|l|}{ Occupation } \\
\hline Informal & 21 & 39.6 \\
\hline Formal & 18 & 34 \\
\hline Student & 4 & 7.5 \\
\hline Unemployed & 10 & 18.9 \\
\hline \multicolumn{3}{|l|}{ Parity } \\
\hline None & 10 & 18.9 \\
\hline Prime & 5 & 9.4 \\
\hline Multipara & 29 & 54.7 \\
\hline Grand-multipara & 9 & 17 \\
\hline \multicolumn{3}{|l|}{ Mode of referral } \\
\hline Self-referral & 25 & 47.2 \\
\hline
\end{tabular}

women who were cohabiting $(6,11.3 \%)$. Women who had secondary or higher education had the least diagnosis $(12,22.6 \%)$, while women with primary education were most diagnosed $(25,47.2 \%)$. Sixteen $(30.2 \%)$ of the women diagnosed had no education at all. Women employed in the informal sector had the highest diagnosis $(21,39.6 \%)$ while unemployed students had the lowest diagnosis (7.5\%). Majority of the women with ectopic pregnancy in this study were multiparous $(29,54.7 \%)$ and the least were primiparous women $(5,9.4 \%)$. Nearly $53 \%$ (28) of the women were referrals and $47.2 \%$ (25) were not.

Table 2 showed the clinical presentation of the women with ectopic pregnancy. Majority of the women presented with lower abdominal pain (52, 98.1\%), abdominal pain 
(50, 94.4\%) and amenorrhea (51, 96.2\%), while some women presented with vaginal bleeding $(37,69.8 \%)$ and the clinical triad (60.4\%). Urine pregnancy test was done for all the women and majority of them tested positive (50,94.3\%). 86.8\% (46) of the women had ultrasound done. Most of the women in this study were anaemic with $26.4 \%$ (14) severely anemic (<7 g/dl), 47.2\% (25) moderately anemic (7 - $9.9 \mathrm{~g} / \mathrm{dl})$, and $15.1 \%$ (8) mildly anemic (10\% - 10.9\%) [16].

Intraoperative findings showed that the fallopian tube was the more frequent site of the ectopic pregnancy $(51,96.2 \%)$, compared to abdominal pregnancy $(2,3.8 \%)$ (Table 3). Of the findings in the fallopian tube, the ampulla was the most common followed by the cornu and ovary corresponding to $78 \%(40)$ and $8 \%(4)$ respectively. There was no case of broad ligament pregnancy (Figure 1). Table 3 also shows that the left fallopian tube was more frequently involved $(32,60.4 \%)$ than the right $(19,35.8 \%)$. Thirty-nine of these women had tubal rupture and hemoperitonuem, 46 had salpingectomy performed, 5 had Salpingoophorectomy and 2 had abdominal excision of the ectopic pregnancy done on them. There was $100 \%$ success in this study as no casualty was recorded all the women in this study successfully had surgery and satisfactorily discharged home.

\section{Discussion}

This study recorded a $2.05 \%$ prevalence of ectopic pregnancy in the VRH. This rate is low relative to prevalence of $10.6 \%$ reported in a study done in Komfo Anokye Teaching Hospital Kumasi Ghana [15], 6.5\% in Nnamdi Azikiwe University teaching hospital

Table 2. Clinical presentation and findings.

\begin{tabular}{ccc}
\hline Presentation & $\mathrm{n}$ & $\%$ \\
\hline Amenorrhea & 51 & 96.2 \\
Vaginal bleeding & 37 & 69.8 \\
Lower abdominal pain & 52 & 98.1 \\
Abdominal tenderness & 50 & 94.3 \\
Classical triad & 32 & 60.4 \\
Other clinical findings & & \\
UPT Done & & \\
Positive & 50 & 94.3 \\
Negative & 3 & 5.7 \\
Ultrasound & & \\
Done & 46 & 86.8 \\
Not done & 7 & 13.2 \\
Haemoglobin & & \\
$<7$ g/dl & 14 & 26.4 \\
7 - 9.9 g/dl & 25 & 47.2 \\
$10-10.9$ g/dl & 8 & 15.1 \\
$\geq 11$ g/dl & 6 & 11.3 \\
\hline
\end{tabular}


Table 3. Surgical findings and management.

\begin{tabular}{ccc}
\hline & $\mathrm{n}(53)$ & $\%$ \\
Site of EP & 51 & 96.2 \\
Fallopian tube & 2 & 3.8 \\
Abdominal & 32 & 60.4 \\
Left fallopian tube & 19 & 35.8 \\
Right fallopian tube & & \\
Tubal rupture \& HP & 39 & 73.6 \\
Yes & 14 & 26.4 \\
No & & \\
Operation performed & 46 & 86.8 \\
Salpingectomy & 5 & 9.4 \\
Salpingoophorectomy & 2 & 3.8 \\
Abdominal excision & & \\
Out come & 53 & 0 \\
Survived & 0 & \\
Died & &
\end{tabular}

HP: Hemoperitoneum.

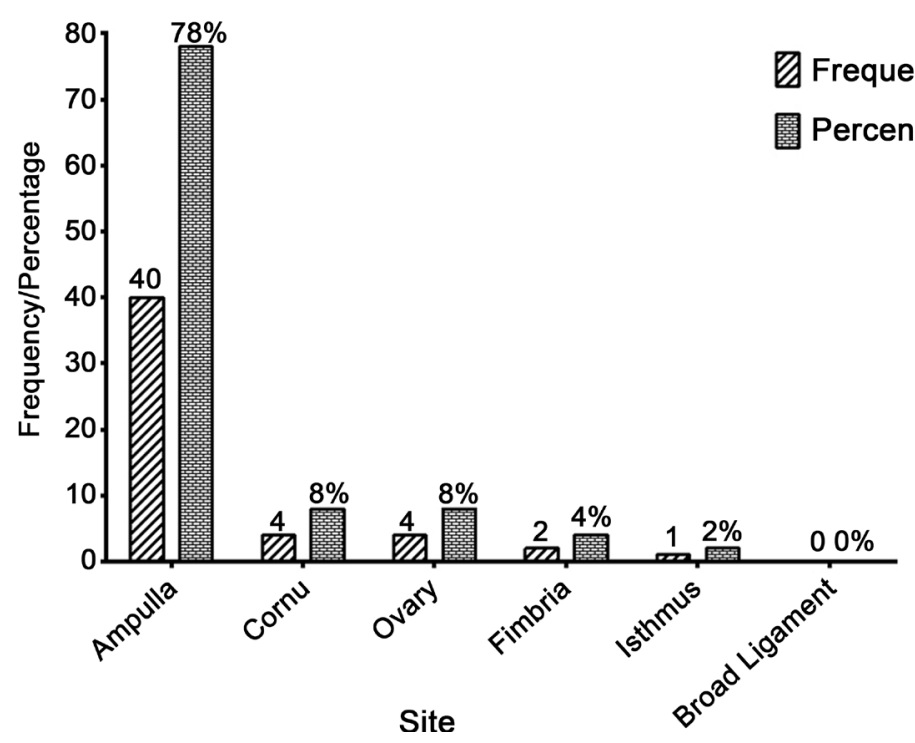

Figure 1. Site of fallopian tube ectopic pregnancy.

Nnewi, Nigeria [17] and 6.9\% in Bugando Medical Centre, Mwanza, Tanzania [18]. All these studies used gynaecological admission as their baseline. The difference between the prevalence of our study and that of others might be attributed 1) to duration of study, 2) patient-hospital dynamics, 3) health seeking behavior of the population and accessibility of health care facilities. Majority of the women in this study are married and between the ages of 21 - 30 with a mean age of 28.8. This is similar to the work 
done in Nigeria and Tanzania [17] [18]. The age range of 21 - 30 and marital status are very likely related to increase sexual activity which might increase the chances of pregnancy. Poor educational background (no formal and primary school education) was predominantly seen in women with ectopic pregnancy in this study, similar to findings in Tanzania study [18]. This finding is corroborated by previous work which suggested that illiteracy negatively impacts on the sexual and general health of women [19] [20].

The clinical presentation of the classical symptoms of lower abdominal pain, vaginal bleeding, amenorrhea and the classical triad in this study were consistent with the findings of other studies done in Africa and Asia [11] [17] [18] [21].

Findings from this study further support the fact that fallopian tube is the commonest site for ectopic pregnancy [1]. Tubal rupture was seen in $73.5 \%$ of the women in this study, probably suggesting late diagnosis of ectopic pregnancy which is common feature in most African settings [8] [14] [17] [18] [21] [22]. The left fallopian tube was more involved with ectopic pregnancy in this study. This is in contrast with studies done in Nigeria and Tanzania [17] [18] [23]. The ampulla was the common site of the fallopian tube that was involve and this is consistent with other studies [18] [24]. Broad ligament ectopic pregnancy was not seen in this study. This is in support of work by others suggesting it is a rare form of ectopic pregnancy, and reported with less frequency [18] [25] [26]. There was no room for tubal conservative management for the women in this study as all the women either had salpingectomy or Salpingoophorectomy. Late diagnosis of the ectopic pregnancy could probably be due to patient time of arrival to hospital or lack of transvaginal ultrasound. These might be responsible for the use of surgery in this study [8] [14] [17]. Though all the women survived the surgery in this study, early diagnosis and nonsurgical conservative management should be the ultimate goal; as radical salpingectomy and salpingoophorectomy aside the physical and psychological trauma on the women, have been implicated in reduced fertility and reoccurrence of ectopic pregnancy [27] [28].

\section{Conclusion}

The $2.05 \%$ prevalence of ectopic pregnancy in no way suggests a regional prevalence. Though the center, where this study, was conducted is the referral hospital for the region, other hospitals clinics in the region might have received and managed cases of ectopic pregnancy. Also some women might not have made it to the hospital. It is very important that a more regional study is conducted to evaluate the burden of this problem. It is also important to educate women on the signs and symptoms of ectopic pregnancy and to equip hospitals and clinics with equipment and skills to make early diagnoses of ectopic pregnancy. A regular scheduled after care should be recommended to conserve the remaining tube.

\section{References}

[1] Crochet, J.R., Bastian, L.A. and Chireau, M.V. (2013) Does This Woman Have an Ectopic Pregnancy?: The Rational Clinical Examination Systematic Review. JAMA, 309, 1722-1729. http://dx.doi.org/10.1001/jama.2013.3914 
[2] Jurkovic, D. and Wilkinson, H. (2011) Diagnosis and Management of Ectopic Pregnancy. BMJ, 342, d3397. http://dx.doi.org/10.1136/bmj.d3397

[3] Saraiya, M., Berg, C.J., Shulman, H., Green, C.A. and Atrash, H.K. (1999) Estimates of the Annual Number of Clinically Recognized Pregnancies in the United States, 1981-1991. American Journal of Epidemiology, 149, 1025-1029.

http://dx.doi.org/10.1093/oxfordjournals.aje.a009747

[4] Storeide, O. (1997) The Incidence of Ectopic Pregnancy in Hordaland County, Norway, 1976-1993. Acta Obstetricia et Gynecologica Scandinavica, 76, 345-349. http://dx.doi.org/10.1111/j.1600-0412.1997.tb07990.x

[5] Mignini, L. (last revised: 26 September 2007) Interventions for Tubal Ectopic Pregnancy; RHL Commentary. The WHO Reproductive Health Library, World Health Organization, Geneva. http://apps.who.int/rhl/gynaecology/lmcom2/en/

[6] Creanga, A.A., Shapiro-Mendoza, C.K., Bish, C.L., Zane, S., Berg, C.J. and Callaghan, W.M. (2011) Trends in Ectopic Pregnancy Mortality in the United States: 1980-2007. Obstetrics \& Gynecology, 117, 837-843. http://dx.doi.org/10.1097/AOG.0b013e3182113c10

[7] Rajkhowa, M. (2000) Trends in the Incidence of Ectopic Pregnancy in England and Wales from 1966 to 1966. BJOG, 107, 369-374. http://dx.doi.org/10.1111/j.1471-0528.2000.tb13233.x

[8] Leke, R.J., Goyaux, N., Matsuda, T. and Thonneau, P.F. (2004) Ectopic Pregnancy in Africa: A Population-Based Study. Obstetrics \& Gynecology, 103, 692-697. http://dx.doi.org/10.1097/01.AOG.0000120146.48098.f2

[9] Condous, G., Okaro, E., Khalid, A., Lu, C., Van Huffel, S., Timmerman, D. and Bourne, T. (2005) The Accuracy of Transvaginal Ultrasonography for the Diagnosis of Ectopic Pregnancy Prior to Surgery. Human Reproduction, 20, 1404-1409. http://dx.doi.org/10.1093/humrep/deh770

[10] Bhatt, S., Ghazale, H. and Dogra, V.S. (2007) Sonographic Evaluation of Ectopic Pregnancy. Radiologic Clinics of North America, 45, 549-560. http://dx.doi.org/10.1016/j.rcl.2007.04.009

[11] Wong, E. and Suat, O.S.B. (2000) Ectopic Pregnancy-A Diagnostic Challenge in the Emergency Department. European Journal of Emergency Medicine, 7, 189-194. http://dx.doi.org/10.1097/00063110-200009000-00005

[12] Dart, R.G., Kaplan, B. and Varaklis, K. (1999) Predictive Value of History and Physical Examination in Patients with Suspected Ectopic Pregnancy. Annals of Emergency Medicine, 33, 283-290. http://dx.doi.org/10.1016/S0196-0644(99)70364-1

[13] Wedderburn, C.J., Warner, P., Graham, B., Duncan, W.C., Critchley, H.O.D. and Horne, A.W. (2010) Economic Evaluation of Diagnosing and Excluding Ectopic Pregnancy. $\mathrm{Hu}$ man Reproduction, 25, 328-333.

[14] Obed, S. (2006) Diagnosis of Unruptured Ectopic Pregnancy Is Still Uncommon in Ghana. Ghana Medical Journal, 40, 3-7.

[15] Opoku, B.K., Nguah, S.B. and Azanu, W. (2013) Ectopic Pregnancy: Are Fair-Colored Women at Increased Risk? Gynecology, 1, 1. http://dx.doi.org/10.7243/2052-6210-1-1

[16] Ghana Statistical Service (GSS), Ghana Health Service (GHS) and ICF International (2015) Ghana Demographic and Health Survey 2014. GSS, GHS, and ICF International, Rockville.

[17] Udigwe, G.O., Umeononihu, O.S. and Mbachu, I.I. (2010) Ectopic Pregnancy: A 5 Year Review of Cases at Nnamdi Azikiwe University Teaching Hospital (NAUTH) Nnewi. Nigerian Medical Journal, 51, 160-163. 
[18] Sr. Nathalia Thobias Makunja. (2013) Clinical Presentation and Factors Associated with Long Hospital Stay among the Suspects of Ectopic Pregnancy at Bugando Medical Centre Mwanza Tanzania. MSc Dissertation, Catholic University of Health and Allied Sciences, Mwansa.

[19] Kickbusch, I.S. (2001) Health Literacy: Addressing the Health and Education Divide. Health Promotion International, 16, 289-297. http://dx.doi.org/10.1093/heapro/16.3.289

[20] Jones, S. and Norton, B. (2007) On the Limits of Sexual Health Literacy: Insights from Ugandan Schoolgirls. Diaspora, Indigenous, and Minority Education, 1, 285-305. http://dx.doi.org/10.1080/15595690701563998

[21] Yakasai, I.A., Abdullahi, J. and Abubakar, I.S. (2012) Management of Ectopic Pregnancy in Aminu Kano Teaching Hospital Kano Nigeria: A 3-Year. Global Advanced Research Journal of Medicine and Medical Sciences, 1, 181-185.

[22] Amoko, D.H. and Buga, G.A. (1995) Clinical Presentation of Ectopic Pregnancy in Transkei, South Africa. East African Medical Journal, 72, 770-773.

[23] Musa, J., Daru, P.H., Mutihir, J.T. and Ujah, I.A. (2008) Ectopic Pregnancy in Jos Northern Nigeria: Prevalence and Impact on Subsequent Fertility. Nigerian Journal of Medicine, 18, 35-38.

[24] Thonneau, P., Hijazi, Y., Goyaux, N., Calvez, T. and Keita, N. (2002) Ectopic Pregnancy in Conakry, Guinea. Bulletin of the World Health Organization, 80, 365-370.

[25] Cheung, C.S.Y. and Cheung, V.Y. (2014) Broad Ligament Ectopic Pregnancy.

[26] Atis, A., Gunduz, O.D. and Tolga Karacan, K.A. (2014) A Rare Form of Ectopic Pregnancy on Mesoovarium, Case Report. Journal of Clinical Case Reports, 4, 359.

[27] Yao, M. and Tulandi, T. (1997) Current Status of Surgical and Nonsurgical Management of Ectopic Pregnancy. Fertility and Sterility, 67, 421-433. http://dx.doi.org/10.1016/S0015-0282(97)80064-7

[28] Bangsgaard, N., Lund, C.O., Ottesen, B. and Nilas, L. (2003) Improved Fertility Following Conservative Surgical Treatment of Ectopic Pregnancy. BJOG, 110, 765-770. http://dx.doi.org/10.1111/j.1471-0528.2003.02253.x

Submit or recommend next manuscript to OALib Journal and we will provide best service for you:

- Publication frequency: Monthly

- 9 subject areas of science, technology and medicine

- Fair and rigorous peer-review system

- Fast publication process

- Article promotion in various social networking sites (LinkedIn, Facebook, Twitter, etc.)

- Maximum dissemination of your research work

Submit Your Paper Online: Click Here to Submit

Contact Us: service@oalib.com 